(2) Open Access Full Text Article

\title{
Personalized treatment in advanced ALK-positive non-small cell lung cancer: from bench to clinical practice
}

This article was published in the following Dove Press journal:

OncoTargets and Therapy

17 October 2016

Number of times this article has been viewed

\author{
Antonio Passaro' \\ Chiara Lazzari ${ }^{1,2}$ \\ Niki Karachaliou ${ }^{3}$ \\ Gianluca Spitaleri' \\ Alessia Pochescil \\ Chiara Catania' \\ Rafael Rosell ${ }^{4}$ \\ Filippo de Marinis' \\ 'Division of Thoracic Oncology, \\ European Institute of Oncology, \\ Milan, Italy; ${ }^{2}$ Department of Medical \\ Oncology, Division of Experimental \\ Medicine, San Raffaele Scientific \\ Institute, Milan, Italy; ${ }^{3}$ Oncology \\ Institute Dr Rosell, Quiron-Dexeus \\ University Hospital, Barcelona, Spain; \\ ${ }^{4}$ Catalan Institute of Oncology, \\ Hospital Germans Trias i Pujol, \\ Badalona, Spain
}

\begin{abstract}
The discovery of anaplastic lymphoma kinase (ALK) gene rearrangements and the development of tyrosine kinase inhibitors (TKI) that target them have achieved unprecedented success in the management of patients with ALK-positive non-small cell lung cancer (NSCLC). Despite the high efficacy of crizotinib, the first oral ALK TKI approved for the treatment of ALK-positive NSCLC, almost all patients inevitably develop acquired resistance, showing disease progression in the brain or in other parenchymal sites. Second- or third-generation ALK TKIs have shown to be active in crizotinib-pretreated or crizotinib-naïve ALK-positive patients, even in those with brain metastases. In this review, the current knowledge regarding ALK-positive NSCLC, focusing on the biology of the disease and the available therapeutic options are discussed.
\end{abstract}

Keywords: ALK, NSCLC, crizotinib, ceritinib, alectinib, brigatinib, lorlatinib, brain metastases

\section{Introduction}

Lung cancer is one of the leading causes of cancer death worldwide, ${ }^{1}$ and non-small cell lung cancer (NSCLC) accounts for $\sim 80 \%-85 \%$ of cases. The majority of patients are diagnosed when the disease is locally advanced or metastatic, with an estimated 5 -year overall survival (OS) of only $16 \%$. In recent years, molecular alterations vulnerable to targeted inhibition have been identified in NSCLC, ${ }^{2}$ and nationwide programs have assessed the feasibility of molecular screening in these patients. One of the first large-scale genotyping analyses investigated the presence of activating mutations in the tyrosine kinase (TK) domain of the epidermal growth factor receptor (EGFR) gene in 2,105 patients with NSCLC from 129 Spanish institutions. ${ }^{3}$ EGFR mutations were detected in $16.6 \%$ of patients. ${ }^{3}$ Similarly, the Lung Cancer Mutation Consortium evaluated actionable drivers in 10 genes in 1,102 patients with NSCLC from 14 American centers ${ }^{4}$ and detected an oncogenic driver in $64 \%$ of cases. Molecular profiling was used to select therapies or enroll patients into clinical trials, and those patients with oncogenic driver alterations who received a targeted therapy had a significant improvement in OS compared with either those with genetic alterations but not treated with targeted agents or those with no druggable target. ${ }^{4}$ The greatest OS improvement was observed in the small group of patients harboring EGFR-activating mutations or the gene rearrangement between echinoderm microtubule-associated protein like 4 and anaplastic lymphoma kinase (EML4-ALK). ${ }^{4}$

The EML4-ALK fusion gene was identified for the first time in 2007 in DNA from a 62-year-old male patient with lung adenocarcinoma. ${ }^{5}$ In November 2011,
Correspondence: Antonio Passaro Division of Thoracic Oncology, European Institute of Oncology, Via G Ripamonti, 435, 20 I4I Milan, Italy

$\mathrm{Tel}+39257489482$

Fax +39294379235

Email antonio.passaro@ieo.it 
crizotinib, a first-in-class ALK inhibitor originally developed as a epitethelial-mesenchymal transition (EMT) inhibitor, was granted accelerated approval by the US Food and Drug Administration (FDA) for the treatment of ALKpositive NSCLC based on the results of a phase I/II study. ${ }^{6}$ In July 2012, crizotinib received a conditional marketing authorization by the European Medicines Agency (EMA) for patients with ALK-positive NSCLC progressing to first-line platinum-based chemotherapy. The confirmatory results of the PROFILE 1007 trial, ${ }^{7}$ showing progressionfree survival (PFS) advantage of crizotinib over second-line chemotherapy, led to the FDA approval of crizotinib in November 2013. After only 2 years (November 2015), the EMA approved the expanded use of crizotinib in patients with ALK-positive treatment-naïve NSCLC based on the results of the PROFILE 1014 study $^{8}$ that compared crizotinib with first-line platinum-based chemotherapy.

Significant progress in understanding the biology of ALK-positive tumors has been made, and the treatment of the disease has improved with potent second- and thirdgeneration ALK inhibitors. The current review focuses on the biology of ALK-positive NSCLC, the currently available therapeutic options for those patients who often suffer from brain metastases, the mechanisms of acquired resistance to ALK inhibitors and the ongoing therapeutic strategies to overcome resistance.

\section{Biology of EML4-ALK tumors}

The EML4-ALK gene is the result of a chromosome rearrangement between the N-terminal portion of the EML4 gene and the TK domain of the ALK gene that belongs to the insulin receptor kinase superfamily. ${ }^{5}$ Both are located in opposite orientations on the short arm of the chromosome 2 (2p). The EML4-ALK fusion gene comes from an inversion on $2 p$ that joins exons 1-13 of EML4 to exons 20-29 of ALK. ${ }^{9,10}$ The resulting fusion protein, EML4-ALK, contains an $\mathrm{N}$-terminus derived from EML4 and a C-terminus containing the entire TK domain of ALK. ${ }^{5}$ Currently, 15 variants have been described, with variant 1 (exons 1-13), variant 2 (exons 1-20), and variant 3 (exons 1-6) being the most common. Variants $3 \mathrm{a}$ and $3 \mathrm{~b}$ derive from an alternative splicing of 33 bp within exon 6 (Figure 1). ${ }^{11,12}$

The primary sequence of the EML4 portion is composed of different domains: the hydrophobic EMAP-like protein (HELP) domain, which is linked to a variable number of tryptophan-aspartic acid (WD) repeats separated from the

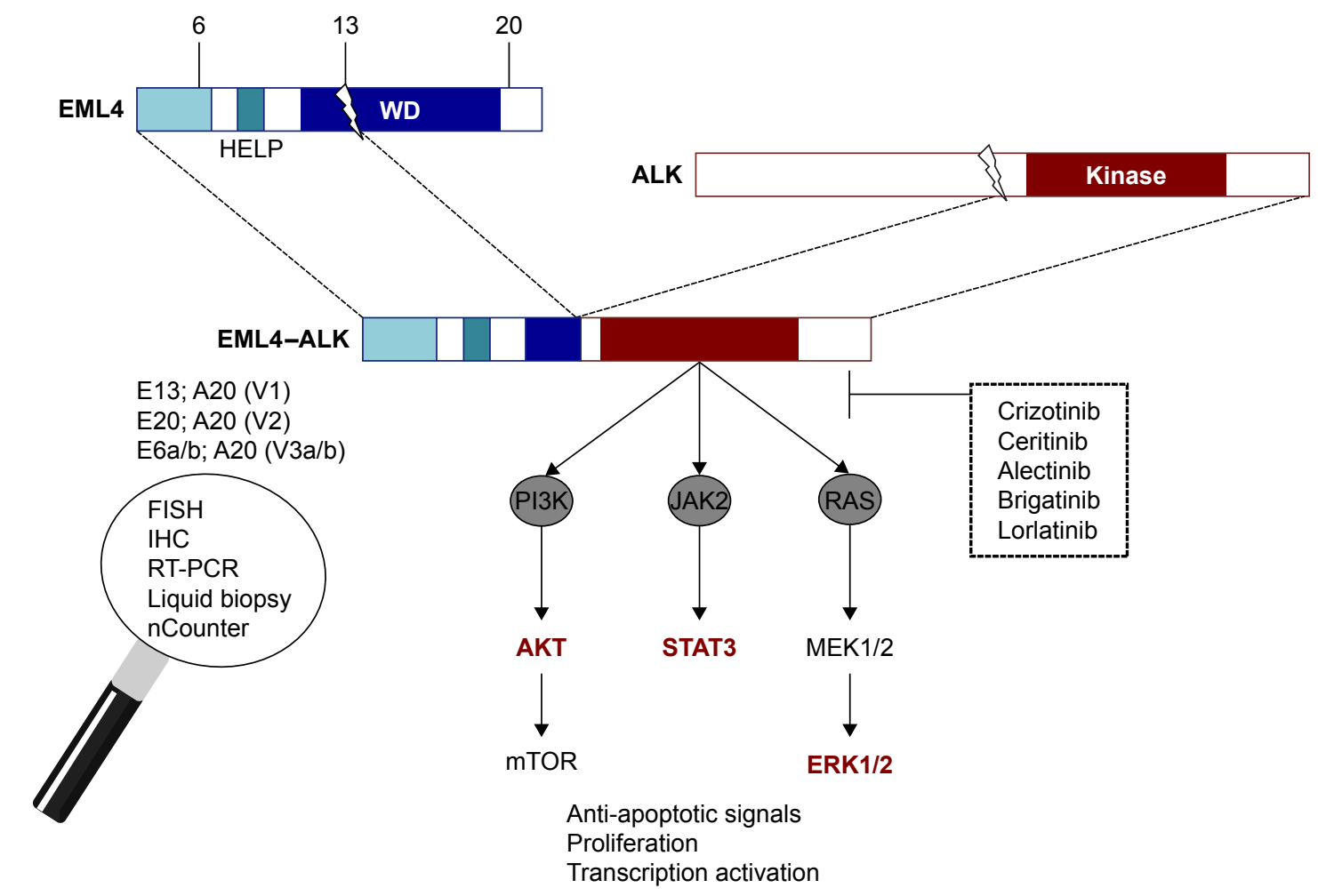

Figure I ALK signaling pathway.

Abbreviations: ALK, anaplastic lymphoma kinase; EML4, echinoderm microtubule-associated protein like 4; FISH, fluorescence in situ hybridization; HELP, hydrophobic EMAP-like protein; IHC, immunohistochemistry; mTOR, mammalian target of rapamycin; PI3K, phosphatidylinositol 3-kinase; RT-PCR, reverse transcription polymerase chain reaction; STAT3, signal transducer and activator of transcription 3; WD, tryptophan-aspartic acid. 
N-terminal coiled coil by a basic region, consisting of serine, threonine and basic residues. ${ }^{9}$ The crystallographic structure of EML4 indicates that the N-terminal domain undergoes a self-trimerization process, ${ }^{13}$ and the HELP-WD region includes a pair of $\beta$-propeller, forming an angle of $50^{\circ} .{ }^{14}$ Each $\beta$-propeller is composed of seven blades, consisting of antiparallel $\beta$-sheet. The blades spanning from residues 230 to 540 are located at the N-terminal part of the sequence, while those from residues 542 to 815 are located at the C-terminal portion. The blade 12 is divided into two subdomains, the $12 \mathrm{~N}$ and the $12 \mathrm{C}$, located in distant regions of the primary sequence. For this reason, the tertiary structure of the HELP-WD region creates a tandem atypical propeller EML (TAPE) domain, in which the HELP motif is part of the hydrophobic core and is crucial in maintaining folding of the TAPE region. ${ }^{14}$ While the trimerization domain and the basic region are the most critical in inducing oncogene transformation, ${ }^{5}$ the TAPE domain influences protein stability. Variants 1 and 2, in which the break point occurs within the $\mathrm{N}$-terminal and the $\mathrm{C}$-terminal $\beta$-propeller, respectively, include a partial TAPE domain only. This determines the exposure of the hydrophobic core, thus rendering the protein unstable and requiring binding with a chaperone to avoid the protein misfolding. By contrast, variants $3 \mathrm{a} / \mathrm{b}$ and 5 lack the TAPE domain and are more stable. ${ }^{14}$ In vitro data indicate that the stability of the protein might influence sensitivity to treatment. ${ }^{12,15}$

Following the activation of the EML4 N-terminal domain, the TK domain undergoes autophosphorylation and favors the induction of the downstream signaling pathways including RAS-mitogen-activated protein kinase (MAPK), phospholipase $\mathrm{C} \gamma$, phosphatidylinositol 3-kinase (PI3K)AKT-mammalian target of rapamycin (mTOR) and janus kinase/signal transducer and activator of transcription (STAT) ${ }^{16,17}$ It is not yet fully understood which signaling pathway is most critical for the growth of tumor. According to the available data, the main downstream pathways may vary among EML4-ALK variants. In the variant 1 positive H3122 cell line, ALK inhibition downregulates ALK, STAT3, ERK, and AKT phosphorylation. ${ }^{18}$ However, while the inhibition of MEK reduces cells growth similarly as observed after crizotinib treatment, conversely when RAS is constitutively active, the tumor cells continue to grow in the presence of an ALK inhibitor. This is not the case for AKT or STAT3, whose hyperactivation either does not or only partially rescues cells from ALK inhibition. ${ }^{18}$ These data suggest that RAS represents the main downstream effector in NSCLC cell lines expressing EML4-ALK variant 1, thus contributing to the development of escape mechanisms. The HELP domain seems to interact with the cell membrane, facilitating the anchorage and activation of RAS. By contrary, the EML4-ALK variant 3 lacks the HELP domain and does not stimulate RAS signaling.

Recent evidence indicates that EML4-ALK activation favors upregulation of programmed cell death ligand 1 (PD-L1) that promotes the development of immune escape. Preclinical data showed that the MAPK and PI3K-AKT downstream signaling pathways induce PD-L1 expression which is suppressed by ALK inhibition. PD-L1 overexpression, measured by flow cytometry and quantitative reverse transcription polymerase chain reaction (qRT-PCR), has been described in EML4-ALK-positive NSCLC cell lines. Moreover, high levels of PD-L1, evaluated by immunohistochemistry (IHC), are detected in tissue from patients with ALK-positive NSCLC. ${ }^{19}$

EML4-ALK translocations have been found in $\sim 5 \%$ of patients with NSCLC, most frequently in never or light smokers, non-Asians, median age of 52 years and adenocarcinoma histology. ${ }^{20}$ Among the different subtypes of adenocarcinoma, the EML4-ALK translocation is more frequently expressed in patients with acinar, papillary, cribriform, mucin-producing pattern or signet ring pattern. ${ }^{21,22}$ EML4-ALK gene fusion is generally mutually exclusive to other known oncogene mutations, although sporadic cases of patients with NSCLC harboring concomitant EGFR-activating mutations have been described in the literature. ${ }^{23}$ Laser capture microdissection was used to separate pure tumor cell subpopulations within different tumor areas, selected according to the adenocarcinoma pattern, in 629 patients with lung adenocarcinoma, and analyzed for EGFR-activating mutations and EML4-ALK fusion. ${ }^{24}$ A total of 20 patients were positive for EML4-ALK, and in two cases a concomitant EGFR mutation was identified. However, in lung cancer cell lines, EML4-ALK and EGFR mutations were not concomitantly present, ${ }^{25}$ suggesting intratumoral heterogeneity.

\section{Cancer stem cells (CSCs) and their role in EML4-ALK tumorigenesis}

In vitro studies in NSCLC cell lines indicate that EML4ALK gene rearrangement upregulates the expression of CSC-related molecules such as NANOG, octamer-binding transcription factor 4 (OCT4) and aldehyde dehydrogenase. ${ }^{26}$ In contrast, crizotinib or ALK-specific small interfering RNA reduces their expression, suggesting that CSC-like property is mainly driven by ALK downstream effectors. The mTOR 
contributes to maintaining the CSC phenotype. ${ }^{27}$ ALK inhibition reduces the AKT phosphorylation at threonine 308 and suppresses mTOR. The treatment of ALK-positive NSCLC cell lines with the mTOR inhibitor rapamycin reduced NANOG and OCT4 expression, and the concomitant use of crizotinib and rapamycin was highly synergistic and significantly reduced the expression of CSC markers. These findings indicate that reversing the CSC-like properties with mTOR inhibitors could delay the emergence of ALK TK inhibitor (TKI) resistance.

\section{Methods for detecting EML4-ALK rearrangements}

Different methods are used to detect the EML4-ALK fusion gene, including fluorescence in situ hybridization (FISH), RT-PCR and IHC. The Vysis Dual color break-apart FISH (Abbott Molecular, Des Plaines, IL, USA) is FDA approved for the diagnosis of patients with ALK-positive NSCLC. The test is considered positive when $>15 \%$ of tumor cells, in at least four fields, show a split of more than two signal diameters between the red and the green signals, labeling the $3^{\prime}$ end of the ALK gene and the $5^{\prime}$ end of the EML4, respectively. FISH is also considered positive in the presence of a single red pattern in $>15 \%$ of tumor cells. The $15 \%$ cutoff selected by FDA represents the percentage of cells that are able to differentiate true positive cases from background noise. The disadvantage of using FISH is that it is an operator-dependent technique whose interpretation can vary, determining the occurrence of false-negative diagnoses or false-positive results in the case of DNA stretching or nuclear sectioning. Furthermore, FISH does not discriminate between the different ALK fusion types. ${ }^{28}$

A growing body of evidence suggests that IHC is a reliable, economic alternative to FISH for the diagnosis of ALK-positive NSCLC. Among the different commercially available ALK antibodies, the DF53 (Cell signaling Technology, Danvers, MA, USA), and the 5A4 (Novocastra; Leica Biosystems, Newcastle Upon Tyne, UK) clones are those mostly used. In June 2015, the DF53 clone was FDA approved as a companion diagnostic test to assess EML4-ALK in NSCLC. It is based on a dichotomic algorithm (positive or negative) depending on the differential signal observed between the specific immunoreaction and the background. The Novocastra system is based on a score $(0,+1,+2,+3)$, in which samples labeled as +1 or +2 need further evaluation by FISH, since $4 \%$ of patients scored with IHC $1+$ and $60 \%$ of those with IHC $2+$ have a FISHpositive result. Recently, the sensitivity, specificity, positive predictive value (PPV), and negative predictive value (NPV) of both antibodies were compared in 1,031 patients with lung adenocarcinoma. ${ }^{29}$ FISH analysis was the reference test and was positive in $3.2 \%$ of cases. The Ventana System resulted in 90.9\% sensitivity, 99.8\% specificity, 93.8\% PPV, and $99.7 \%$ NPV. Similar were the results from the analysis performed with the Novocastra antibody: $99.7 \%$ sensitivity, 98.3\% specificity, 99.7\% NVP and 63.8\% PPV. The lower $\mathrm{PPV}$ is probably related to the presence of a large amount of false-positive results scored as IHC 1+. Five FISH/IHC discordant cases (with both antibodies) were observed and analyzed by next-generation sequencing (NGS) that confirmed the FISH data. Three received crizotinib, and response was observed in two cases: one patient was IHC positive and FISH and NGS negative, while the other was IHC negative and FISH and NGS positive.

Another methodology to detect ALK fusions is RT-PCR. The advantage of RT-PCR is that it defines the ALK partner and the fusion variant, although multiple primers are needed. In a cohort of 200 patients with NSCLC in whom EML4-ALK was examined, RT-PCR was positive in $12.5 \%$ of cases, while FISH was positive in only $4.5 \%{ }^{30}$ These data suggest that IHC, FISH, and RT-PCR provide complementary information to identify ALK-positive patients.

An alternative method to detect ALK fusions is the NanoString nCounter gene expression platform. ${ }^{31}$ It is based on two nCounter probes that specifically hybridize RNA: the $3^{\prime}$ ALK reporter probe, consisting of 50 biotinylated oligonucleotides labeled with fluorophores ${ }^{32}$ for signal detection, and the $5^{\prime}$ EML4 capture probe, composed of 50 biotinylated oligonucleotides that capture mRNA. A quantitative PCR is performed and the value obtained is compared with a previously determined reference cutoff value. A high concordance of around 93\% was observed between nCounter and FISH or IHC. The main advantage of the nCounter platform is that it requires a small amount of tumor tissue.

Numerous methods to detect tumor aberrations in blood have been developed in the search for an accessible, minimally invasive way to identify and track molecular alterations. For instance, the relevance of circulating tumor cells as a surrogate for biopsy-based FISH testing has been thoroughly examined. ${ }^{33-35}$ Interestingly, tumor cells release RNA sequestered by platelets, making them an important biosource for molecular screening. ${ }^{36-39}$ Recently, the EML4-ALK rearrangement was examined in the platelets of 77 patients with NSCLC, 38 of whom were ALK positive by FISH or RT-PCR in tissue. ${ }^{40}$ Platelet RNA was isolated from 62 patients, 34 of whom were ALK positive in tissue. 
Platelet RNA was identified as ALK positive in 22 cases, indicating a sensitivity of $65 \%$ and a specificity of $100 \%$. Interestingly, in the subset of 29 crizotinib-treated patients, PFS was 3.7 months for patients in which the EML4-ALK rearrangement continued to be detected in platelets in the course of treatment and 16 months for those with ALK platelets. ${ }^{40}$ Platelets were used to monitor disease evolution in a crizotinib-treated patient. The EML4-ALK rearrangement was identified at baseline but was not detectable at the time of response. Furthermore, the ALK fusion gene reappeared during a 1-month interruption of crizotinib and disappeared again when the patient restarted treatment. Finally, the ALK rearrangement was identified 2 months before radiologic tumor progression. ${ }^{40}$ Therefore, platelet RNA may be a valid tool to monitor treatment in patients with ALK-positive NSCLC.

\section{First-generation inhibitor: crizotinib}

Crizotinib, an orally bioavailable small molecule, is the first ALK TKI evaluated and approved for the treatment of patients with ALK-positive NSCLC (Figure 2). Preclinical studies demonstrated that crizotinib inhibits cell proliferation and promotes apoptosis in ALK-positive anaplastic large cell lymphoma cells. Crizotinib also inhibits EMT and ROS1, a kinase that shares $77 \%$ of amino acid sequences of adenosine triphosphate (ATP)-binding sites with the ALK. ${ }^{41,42}$

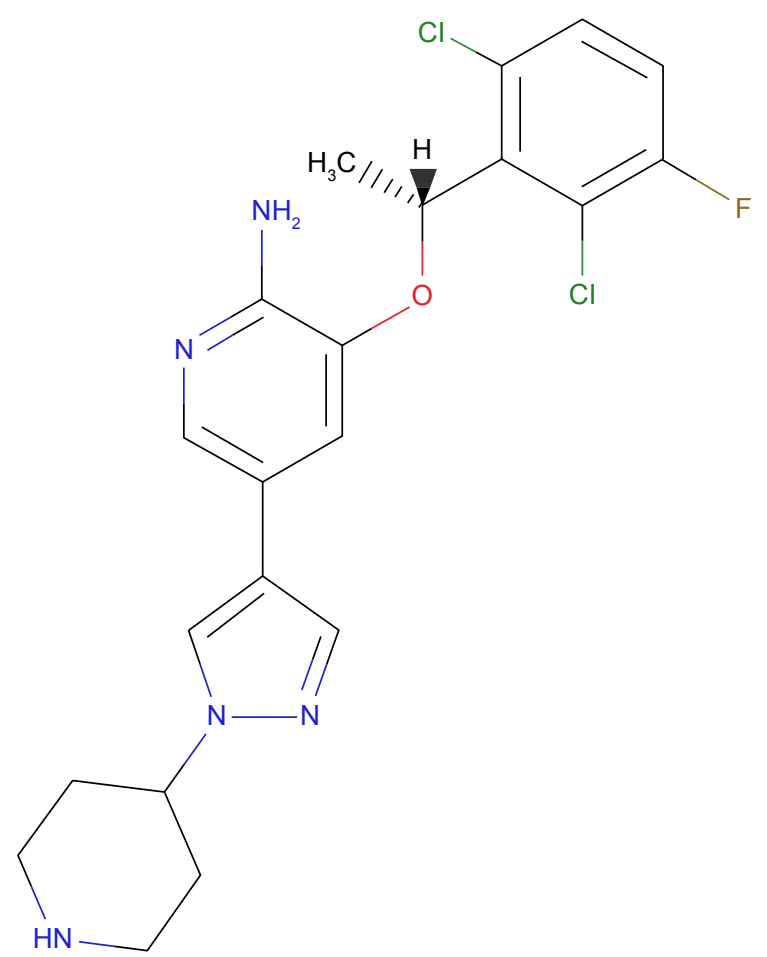

Figure 2 Crizotinib structure.
The phase I PROFILE 1001 trial evaluated the pharmacokinetic profile and efficacy of crizotinib in patients with ALK-positive NSCLC. ${ }^{43}$ Crizotinib was well tolerated at a dose of $250 \mathrm{mg}$ twice daily and the overall response rate (ORR) was $61 \%$, with the median PFS of 9.7 months (Table 1) ${ }^{43}$ The results were confirmed in the phase II PROFILE 1005 study that enrolled patients with advanced previously treated ALK-positive NSCLC and obtained ORR of $60 \%$ and median PFS of 8.1 months (Table 1). ${ }^{44}$ Two phase III clinical trials comparing crizotinib with standard chemotherapy in the first- and second-line settings have been conducted (Table 1). In the PROFILE 1007 trial, patients with advanced or metastatic ALK-positive NSCLC, previously treated with a platinum-based chemotherapy, were enrolled and randomized to receive crizotinib or standard chemotherapy. ${ }^{7}$ Better median PFS was obtained with crizotinib (7.7 months vs 3 months; Table 1). Patients who received pemetrexed had a better outcome in comparison with those receiving docetaxel, a result that can be explained by the lower concentration of thymidylate synthase in ALKpositive tumors. ${ }^{45-47}$

In the PROFILE 1014 study, patients with ALK-positive NSCLC were randomly assigned to receive first-line crizotinib or a platinum-based regimen with pemetrexed. ${ }^{8}$ The results confirmed the high efficacy of crizotinib, with a PFS of 10.9 months compared with 7 months with chemotherapy. The ORR was $74 \%$ with crizotinib and $45 \%$ with chemotherapy (Table 1).

Patients with ALK-positive NSCLC have a high risk of developing brain metastases, as observed in $\sim 30 \%$ of cases at the time of tumor diagnosis ${ }^{48}$ and in $60 \%$ of patients during crizotinib treatment. ${ }^{49}$ The main reason for crizotinib failure in brain disease is its poor blood-brain barrier penetration. ${ }^{50} \mathrm{~A}$ retrospective analysis performed in 90 patients with ALK-positive NSCLC with brain lesions treated with ALK inhibitors showed that half of the patients had multiple brain metastases at the time of diagnosis. ${ }^{24}$ Out of 90 patients, 84 received brain radiotherapy, while six received only ALK TKIs. Despite the high percentage of brain progressions, the median OS was 49.5 months, thanks to the use of local brain therapies (whole brain radiotherapy, radiosurgery, or surgery).

A retrospective analysis of the PROFILE 1005 and 1007 trials assessed the activity of crizotinib in stable brain metastases in patients either previously treated or untreated with brain radiotherapy ${ }^{49}$ Crizotinib was proved to be active in brain metastases, especially for patients who had previously undergone brain radiotherapy. This analysis documented the intracranial overall response rate (IC-ORR) and 12-week IC 
Table I Clinical trials with ALK inhibitors

\begin{tabular}{|c|c|c|c|c|c|c|}
\hline Trial & Drug & Phase & $\begin{array}{l}\text { No of } \\
\text { patients }\end{array}$ & ORR (\%) & $\begin{array}{l}\text { Median PFS (months) } \\
\text { HR }(95 \% \mathrm{CI})\end{array}$ & $\begin{array}{l}\text { Median OS (months) } \\
\text { HR }(95 \% \mathrm{Cl})\end{array}$ \\
\hline PFI00I 43 & Crizotinib & 1 & 149 & $60.8 \%(52.3-68.9)$ & $9.7(7.7-12.8)$ & - \\
\hline $\mathrm{PFI} 005^{44}$ & Crizotinib & ॥ & 261 & $60 \%(54-66)$ & $8.1(6.8-9.7)$ & - \\
\hline PFI0077 & $\begin{array}{l}\text { Crizotinib vs } \\
\text { pemetrexed/docetaxel }\end{array}$ & III & 347 & $65 \%$ vs $20 \% ; P<0.001$ & $\begin{array}{l}\text { HR: } 0.49 \text { (0.37-0.64); } \\
P<0.00 \text { I }\end{array}$ & $\begin{array}{l}\text { HR: I.02 (0.68-I.54); } \\
P=0.54\end{array}$ \\
\hline $\mathrm{PFIOI} 4^{8}$ & $\begin{array}{l}\text { Crizotinib vs platinum } \\
\text { doublet }\end{array}$ & III & 343 & $74 \%$ vs $45 \% ; P<0.000$ I & $\begin{array}{l}\text { HR: } 0.45(0.35-0.69) \text {; } \\
P<0.00 \text { I }\end{array}$ & - \\
\hline ASCEND- $1^{70}$ & Ceritinib & I & 255 & $\begin{array}{l}72 \% \text { in crizotinib naïve; } \\
56 \% \text { in crizotinib resistant }\end{array}$ & $\begin{array}{l}\text { 18.4 in crizotinib naive; } \\
6.9 \text { in crizotinib resistant }\end{array}$ & - \\
\hline ASCEND- $2^{72}$ & Ceritinib & II & $\begin{array}{l}\text { I } 40 \text { crizotinib- } \\
\text { resistant }\end{array}$ & $38.6 \%(30.5-47.2)$ & $5.7(5.4-7.6)$ & - \\
\hline ASCEND-373 & Ceritinib & ॥ & $\begin{array}{l}\text { I } 24 \text { crizotinib- } \\
\text { naïve }\end{array}$ & $63.7 \%(54.6-72.2)$ & I I.I (9.3-NE) & - \\
\hline AF-00 IJPP 79,80 & Alectinib & I-II & $\begin{array}{l}46 \text { crizotinib- } \\
\text { naïve }\end{array}$ & $93.3 \%(82.1-98.6)$ & - & - \\
\hline$A F-002 J G^{81}$ & Alectinib & $\mid-I I$ & $\begin{array}{l}47 \text { crizotinib- } \\
\text { resistant }\end{array}$ & $53 \%$ & - & - \\
\hline NP2867384 & Alectinib & II & $\begin{array}{l}138 \text { crizotinib- } \\
\text { resistant }\end{array}$ & $50 \%(4 I-59)$ & $8.9(5.6-11.3)$ & - \\
\hline NP2876/ 85 & Alectinib & I-II & $\begin{array}{l}87 \text { crizotinib- } \\
\text { resistant }\end{array}$ & $48 \%(36-60)$ & - & - \\
\hline NCT0I44946I ${ }^{96}$ & Brigatinib & I & $\begin{array}{l}70 \text { crizotinib- } \\
\text { resistant }\end{array}$ & $71 \%$ & 13.4 & - \\
\hline NCT0197086598 & Lorlatinib & I & 41 & $50 \%$ & 12.9 & - \\
\hline
\end{tabular}

Abbreviations: $\mathrm{ALK}$, anaplastic lymphoma kinase; $\mathrm{Cl}$, confidence interval; $\mathrm{HR}$, hazard ratio; NE, not estimable; ORR, overall response rate; OS, overall survival; PFS, progression-free survival.

disease control rate (IC-DCR) in $18 \%$ and $56 \%$ of patients, respectively. The median IC time to progression (IC-TTP) was 7 months in patients with previously untreated brain metastasis, but results were better for patients previously treated with brain radiotherapy who attained an IC-ORR of $33 \%$, a 12 -week IC-DCR of $62 \%$ and a median IC-TTP of
13.2 months. The PROFILE 1014 trial enrolled 79 patients with brain metastases ${ }^{8}$ and achieved median IC-TTP of 15.7 months in the crizotinib group vs 12.5 months in the chemotherapy group. The 12-week and 24-week IC-DCRs were significantly higher with crizotinib vs chemotherapy ( $85 \%$ vs $45 \%$ and $56 \%$ vs $25 \%$, respectively; Table 2 ). ${ }^{51}$

Table 2 Activity of ALK inhibitors on brain metastases

\begin{tabular}{|c|c|c|c|c|c|c|}
\hline Drug & Trial & Patients with BMa & IC-ORR & IC-DCR & $\begin{array}{l}\text { IC-PFS } \\
\text { (months) }\end{array}$ & $\begin{array}{l}\text { IC-DOR } \\
\text { (months) }\end{array}$ \\
\hline \multirow{4}{*}{ Crizotinib } & PFI005/I00749 & All: 275 & $33 \%$ & $62 \%$ & 13.2 & Not reached \\
\hline & & No RT: 109 & $18 \%$ & $56 \%$ & 7 & 26.4 \\
\hline & $\mathrm{PFIOI} 4^{8}$ & All: 79 & NR & $85 \%$ & 15.7 & NR \\
\hline & & No RT: 0 & NA & NA & NA & NA \\
\hline \multirow[t]{8}{*}{ Ceritinib } & ASCEND- $I^{70}$ & All: 124 & $36 \%$ & $65 \%$ & NR & II.I \\
\hline & & No RT: 23 & $43 \%$ & NR & $N R$ & NR \\
\hline & & No crizotinib: 26 & $63 \%$ & $79 \%$ & NR & 8.2 \\
\hline & & No RT/crizotinib: 8 & $75 \%$ & NR & NR & NR \\
\hline & ASCEND-2 $2^{\mathrm{b}, 72}$ & All: 100 & $39.4 \%$ & $64 \%$ & 6.8 & NR \\
\hline & & No RT: 28 & NR & NR & NR & NR \\
\hline & ASCEND-3 $3^{\mathrm{b}, 73}$ & All: 50 & $58.8 \%$ & $78 \%$ & 11 & NR \\
\hline & & No RT: 23 & NR & NR & NR & NR \\
\hline \multirow[t]{4}{*}{ Alectinib } & NCT0I80IIIII01 & All: 84 & $57 \%$ & $83 \%$ & $24.8 \%^{\mathrm{a}}$ & 10.3 \\
\hline & & No RT: 23 & $43 \%$ & NR & NR & NR \\
\hline & NP2876/ ${ }^{85}$ & All: 52 & $75 \%$ & $63 \%$ & NR & II.I \\
\hline & & No RT: I8 & $67 \%$ & NR & NR & NR \\
\hline \multirow[t]{2}{*}{ Brigatinib } & NCT0I $\left.44946\right|^{b, 95}$ & All: 52 & $53 \%$ & $55 \%$ & 15.6 & NR \\
\hline & & No RT: 25 & $67 \%$ & NR & NR & NR \\
\hline
\end{tabular}

Notes: ${ }^{\mathrm{a}} \mathrm{Data}$ are referred to as IC cumulative incidence rate. ${ }^{\mathrm{b}} \mathrm{Data}$ reported on abstracts.

Abbreviations: ALK, anaplastic lymphoma kinase; BM, brain metastases; IC, intracranial; IC-DCR, intracranial disease control rate; IC-DOR, intracranial median duration of response; IC-ORR, intracranial overall response rate; IC-PFS, intracranial median progression-free survival; NA, not applicable; NR, not reported; RT, radiotherapy. 
However, because all the patients had previously received brain radiation, the IC activity of crizotinib may have been overestimated.

Crizotinib is a well-tolerated treatment, with discontinuation due to treatment-related adverse events (AEs) in only $2 \%-6 \%$ of cases. ${ }^{52}$ Visual disorders, ${ }^{8}$ gastrointestinal toxicity, and peripheral edema represent the most common grade I-II AEs. ${ }^{47}$ Asymptomatic sinus bradycardia and QTc prolongation have also been observed. Neutropenia, lymphopenia, elevated alanine aminotransferase (ALT), and hypophosphatemia are the most frequent treatment-related grade III-IV AEs reported. Cases of pneumonitis have also been reported. Rapid-onset hypogonadism and lower total serum testosterone levels have been described in male patients treated with crizotinib, probably correlated with a central (hypothalamic or pituitary) effect. ${ }^{52}$

Crizotinib was approved in 2011 by the FDA in the US and in 2012 in the EU for the treatment of previously treated $A L K$-positive advanced NSCLC. In 2015, crizotinib received an expansion approval by the EMA, as a first-line treatment of patients with ALK-positive NSCLC. Currently, crizotinib is also approved in $>85$ countries across North and South America and in Asia, with additional marketing applications under review. In addition to the ALK indications, FDA approved crizotinib for patients with ROS1-positive NSCLC in 2016.

\section{Mechanisms of resistance to crizotinib}

Different mechanisms of acquired resistance to crizotinib, including secondary ALK mutations, ALK fusion gene amplification and activation of alternative signaling pathways, have been identified. In the molecular analyses performed in a group of patients with NSCLC who underwent rebiopsies at the time of crizotinib resistance, ${ }^{53,54}$ secondary mutations in the kinase domain of ALK that interfere with drug binding or ATP affinity occurred in $\sim 30 \%$ of cases (Table 2 ). Several ALK mutations have been identified, with L1196M and G1269A being the most common. L1196M (amino acid substitution from leucine [L] to methionine [M]) is located in the gatekeeper residue and causes a steric hindrance for crizotinib binding. ${ }^{55}$ G1269A induces a similar effect, where glycine $(\mathrm{G})$ is substituted for alanine (A). G1269A is located in the ATP-binding pocket and confers crizotinib resistance in vitro. ${ }^{56}$ Additional two point mutations, G1202R, in which arginine (R) substitutes for glycine $(\mathrm{G})$, and S1206Y, where tyrosine $(\mathrm{Y})$ is replaced by serine $(\mathrm{S})$, are located in the solvent front and alter crizotinib binding. The insertion of threonine at position 1151 (1151Tins) increases ATP affinity for ALK. ${ }^{56}$ Two other mutations, C1156Y (amino acid substitution from cysteine [C] to tyrosine [Y]) and L1152R (leucine [L] to arginine [R]), located in a nonactive site, do not directly interact with either crizotinib or ATP. C1156Y induces conformational changes in the binding cavity, thus decreasing interactions between crizotinib and the ALK, ${ }^{57}$ while the biologic bases for resistance mechanisms induced by L1152R are unknown (Table 3). In vitro data indicate that L1152R reduces crizotinib-mediated inhibition of downstream AKT and ERK1/2. ${ }^{58}$ The crystallographic structure of another secondary ALK mutation, ${ }^{59}$ F1174L (amino acid substitution from phenylalanine $[\mathrm{F}]$ to leucine [L]), originally identified in patients with neuroblastoma, ${ }^{60}$ showed that the binding between crizotinib and the mutant kinase is weaker than that observed between crizotinib and the wild-type receptor. Moreover, the native ALK forms two hydrogen bonds with crizotinib, one on the glutamic acid 1197 (E-1197) and

Table 3 Principal ALK mutations of acquired resistance mechanisms

\begin{tabular}{lll}
\hline Type of mutation & Biologic function & Drugs resistant \\
\hline LII96M & Gatekeeper residue & Crizotinib \\
GI269A & ATP-binding pocket & Crizotinib \\
GI20R & Solvent front, steric hindrance & Ceritinib-alectinib \\
SI206Y & Solvent front & Ceritinib-alectinib \\
II5ITins & Increased ATP affinity for ALK & Crizotinib \\
CII56Y & Loop N-terminal of alpha C; increased kinase activity & Crizotinib \\
LII52R & Loop N-terminal of alpha C & Crizotinib-ceritinib \\
FII47L & Decreased stability of ALK-crizotinib complex & Crizotinib \\
FI245C & Near the kinase motif & Crizotinib-ceritinib \\
III7IT (N) & Steric hindrance & Crizotinib \\
FII74C $(V)$ & Conformational changes in the catalytic domain & Alectinib \\
GII23S & Steric hindrance & Ceritinib \\
VII80L & Gatekeeper residue & Alectinib \\
LII98F + CII56Y & Near ATP-binding site, steric hindrance & Ceritinib-alectinib \\
\hline Ab & Ceritinib & Alectinib \\
\hline
\end{tabular}

Abbreviations: ALK, anaplastic lymphoma kinase; ATP, adenosine triphosphate; $N$, asparagine; $V$, valine. 
the other on the methionine 1199 (M-1199), while the mutant kinase displays only the binding with E-1197, decreasing the stability of the ALK-crizotinib complex. Recently, a novel acquired resistance mutation resulting in amino acid substitution from a phenylalanine (F) to a cysteine (C) at position 1245 (F1245C) was identified in a 52-year-old male who developed tumor progression after 27 months of crizotinib treatment and who had complete radiographic response on ceritinib. ${ }^{61} \mathrm{~F} 1245 \mathrm{C}$ mutation has previously been identified in children affected by neuroblastoma, ${ }^{62}$ and it is located near the kinase aspartate-phenylalanine-glycine motif and confers intermediate levels of resistance to crizotinib (Table 2).

The ALK mutants cause less or more resistance to crizotinib, with S1206Y being the least resistant mutation, and 1151Tins and L1196M the most. The presence of ALK L1196M, G1269A, S1206Y, or F1145C confers sensitivity to both ceritinib and alectinib, while $\mathrm{C} 1156 \mathrm{Y}$ and F1174L are sensitive to alectinib only, and G1202R causes steric hindrance to crizotinib, ceritinib, and alectinib, ${ }^{63-66}$ but not to lorlatinib (PF-06463922; Table 3). ${ }^{67}$

Other mechanisms of acquired resistance to crizotinib are ALK amplification, either alone or in combination with a kinase domain mutation, and the activation of alternative receptor TKs, such as KIT amplification, or EGFR or KRAS mutations $.53,54$ Combined ALK and SRC inhibition has been found to be more efficient than ALK inhibition alone in ALKdriven patient-derived models. ${ }^{68}$ In vitro studies showed that the stroma-derived stem cell factor (SCF) is crucial for KIT activation since, only in the presence of SCF, the concomitant administration of crizotinib and imatinib induces a markedly decreased proliferation of cells overexpressing KIT, thus prompting involvement of the tumor microenvironment. In a small number of ALK-positive patients, KRAS and EGFR mutations were found in the post-crizotinib treatment biopsy, suggesting that a second oncogenic driver may be present in the same cell or in separate clonal populations, emerging under selective pressure of treatment with crizotinib. These data strengthen the importance of performing tumor re-biopsy at the time of crizotinib resistance to determine the molecular mechanism of resistance and define the therapeutic strategy to overcome it.

\section{Second-generation ALK inhibitors Ceritinib (LDK378)}

Ceritinib (LDK378) is a small-molecule ATP-competitive ALK TKI that is $\sim 20$ times more potent than crizotinib (Figure 3) ${ }^{69}$ Preclinical models have demonstrated that ceritinib is effective against both crizotinib-sensitive and

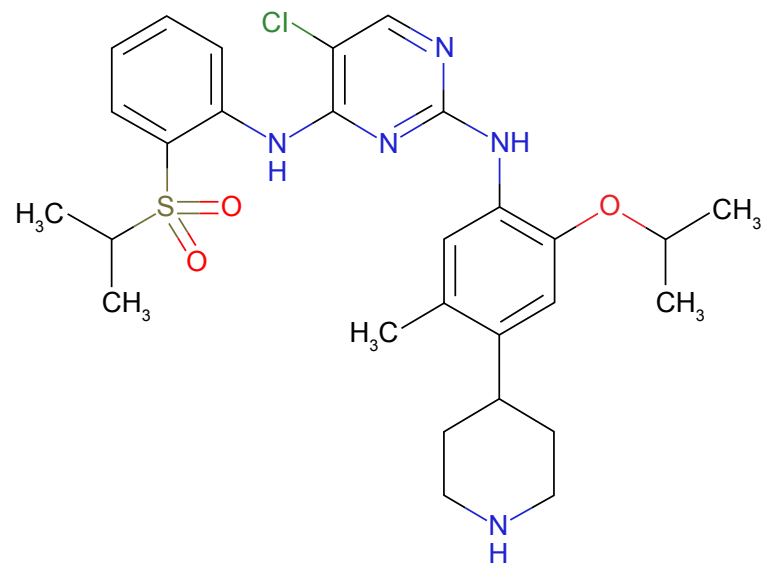

Figure 3 Ceritinib structure.

crizotinib-resistant tumors. In contrast to crizotinib, ceritinib does not inhibit the kinase activity of EMT but inhibits the insulin-like growth factor 1 (IGF-1) receptor. Ceritinib has been shown to strongly inhibit ALK-positive cell lines harboring mutations that cause resistance to crizotinib, especially the L1196M, G1269A, I1171T, and S1206Y. ${ }^{69}$

The efficacy and safety of ceritinib were evaluated in a phase I trial (ASCEND-1) that included patients with ALK-positive NSCLC; both ALK inhibitor naïve and ALK inhibitor pretreated were included. ${ }^{70}$ The ORR was $72 \%$ in ALK inhibitor-naïve patients compared with $56 \%$ in ALK-inhibitor-pretreated patients, and the median PFS was 18.4 months and 6.9 months, respectively (Table 1). Based on these results, the FDA approved ceritinib for patients with advanced or metastatic ALK-positive NSCLC progressing to crizotinib. In Europe, the EMA recommended granting a conditional marketing authorization for ceritinib in patients with ALK-positive NSCLC previously treated with crizotinib. ${ }^{70}$

Half of the patients included in the ASCEND-1 trial had asymptomatic or controlled brain metastases. ${ }^{70}$ In vitro data indicate that ceritinib is efficiently transported by the human ATP-binding cassette subfamily B member 1 (hABCB1) and moderately by the human ATP-binding cassette subfamily $\mathrm{G}$ member 2 (hABCG2). ${ }^{71}$ Moreover, the human blood-brain barrier has a higher expression of hABCG2 than hABCB1, suggesting that $\mathrm{hABCG} 2$ has more influence over the accumulation of ceritinib in the brain. Knockout of Abcb1 and Abcg2 in a mouse model significantly increased the concentration of ceritinib in the brain, although the effect in mice was more related to the activity of Abcb1 than Abcg2. The ongoing ASCEND-7 (NCT02336451) is evaluating the efficacy of ceritinib in patients with ALK-positive NSCLC with brain metastases or leptomeningitis (Table 2). 
Data on the efficacy of ceritinib at brain lesions from the patients enrolled in the phase I and II studies are now available. In the ASCEND-1 trial, the IC-DCR was 79\% for ALK-inhibitor-naïve patients and $65 \%$ for ALK-inhibitorpretreated patients. Among patients with measurable IC lesions at baseline, the IC-ORR was $63 \%$ and $36 \%$ in ALK-inhibitor-naïve and ALK-inhibitor-pretreated patients, respectively. The IC-DCR was $63 \%$ and $61 \%$ in ALK-naïve and ALK-pretreated patients, respectively (Table 2). ${ }^{70}$

The phase II ASCEND-2 trial enrolled 140 patients who had previously received cytotoxic chemotherapy and had also progressed to crizotinib. Brain metastases were observed in $71.4 \% ; 28 \%$ of whom had no prior brain radiation. The ORR was $38.6 \%$ (Table 1). ${ }^{72}$ The median IC-DCR was $64 \%$, and the median IC-TTP was 6.8 months. The phase II ASCEND-3 trial ${ }^{73}$ (ongoing but not currently recruiting participants) is evaluating the role of ceritinib in patients with ALK-positive crizotinib-naïve NSCLC. Approximately $40 \%$ of the enrolled patients have brain metastases at baseline and $46 \%$ had not received prior brain radiation. In patients with measurable brain lesion, a median IC-DCR of $78 \%$ was observed (Table 2 ). ${ }^{73}$ Two ongoing phase III trials, ASCEND-4 (NCT01828099) and ASCEND-5 (NCT01828112), are comparing the efficacy of ceritinib with first- and second-line chemotherapy, respectively. ${ }^{74}$ The ASCEND-7 (NCT02336451) is evaluating the efficacy of ceritinib in patients with ALK-positive NSCLC with brain metastases or leptomeningitis.

Grade III/IV AEs related to ceritinib treatment occur in almost half of the patients and serious AEs, suspected to be drug related, in $12 \%$. Gastrointestinal toxicity is the most frequent AE, occurring in $99 \%$ of cases. Grade III/IV increases in ALT and aspartate aminotransferase (AST) are also frequent and manageable with dose interruption. ${ }^{70,72,74}$

Ceritinib was approved in 2014 by FDA in the US and in 2015 by EMA in the EU for the treatment of ALK-positive NSCLC with disease progression on or who are intolerant to crizotinib. Outside the US and EU, ceritinib is now approved for the same indication, in other countries within North/South America and Asia.

\section{Mechanisms of resistance to ceritinib}

Results from tumor re-biopsies performed at the time of resistance to ceritinib showed the emergence of secondary ALK mutations, including G1202R, F1174C, and F1174V. ${ }^{63}$ Recently, a novel ALK mutation was identified in a 58-yearold ALK-positive patient who progressed on ceritinib treatment. The mutation consists of a substitution from glycine $(\mathrm{G})$ to serine (S) at codon 1123 (G1123S; Table 3), ${ }^{75}$ which sterically prevents binding between ceritinib and ATP. Moreover, increased phosphorylation of EGFR, IGF receptor 1 (IGF-1R), and human epidermal growth factor receptor 3 (HER3) was observed in ALK-positive NSCLC cell lines with acquired resistance to ceritinib. High mRNA expression of epidermal growth factor (EGF), IGF, and neuregulin 1 (NRG-1), the ligand of HER3, and the presence of heterodimeric complexes between HER3 and EGFR were detected, suggesting that the activation of the NRG-1-EGFR-HER3 signaling axis may mediate acquired resistance to ceritinib. ${ }^{76}$ Finally, once acquired resistance to ceritinib has developed; the combination of MEK and ALK inhibitors may have a therapeutic benefit, as has been demonstrated in patient-derived models. ${ }^{68}$

\section{Alectinib (RO5424802)}

Alectinib is a highly potent selective oral ALK TKI active in crizotinib-naïve and crizotinib-resistant ALK-positive NSCLC, with proven activity against the L1196 gatekeeper mutation and others such as C1156Y, F1174L, R1275Q, and G1269A, but not against ROS1 and IGF-1R (Figure 4). ${ }^{64,77,78}$ Two phase I/II trials have evaluated the efficacy and safety of alectinib in ALK-positive NSCLC (Table 1). In the AF-001JP trial, conducted in Japan, 70 patients with ALK-positive crizotinib-naïve NSCLC were enrolled. ${ }^{79}$ In the phase I part, $300 \mathrm{mg}$ of alectinib twice daily was defined as the recommended dose for the phase II. The ORR of crizotinib-naïve patients entered in the phase II part of the trial was $93.5 \%$,

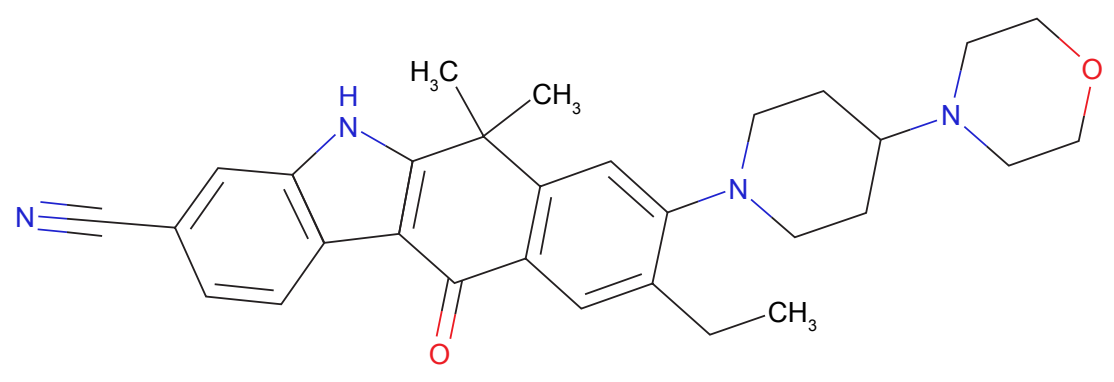

Figure 4 Alectinib structure. 
with a PFS at 12 months of $83 \% .{ }^{80}$ Based on the results of the AF-001JP trial, alectinib received approval in Japan for the treatment of patients with ALK-positive NSCLC who had not previously received other ALK inhibitors. In the AF-002JG phase I/II study, conducted in the US, 47 patients with ALKpositive NSCLC who had progressed on or were intolerant to crizotinib were enrolled. ${ }^{81}$ In the phase I part, $600 \mathrm{mg}$ of alectinib twice daily was defined as the recommended dose for the phase II. The ORR to alectinib in the phase II part of the trial was $55 \%$ (Table 1). Out of 47 enrolled patients, 21 had asymptomatic brain metastases, ${ }^{81}$ and six of the 21 had a complete response, five had a partial response, and eight had stable disease. One patient with leptomeningeal metastases attained a partial response. Moreover, cerebrospinal fluid (CSF) pharmacokinetic data were available for five of these patients. There was a linear association between alectinib unbound serum concentrations and CSF concentrations, while the concentration in the CSF was $2.69 \mathrm{nmol} / \mathrm{L}$, which is above than its $\mathrm{IC}_{50}$ concentrations for ALK inhibition. ${ }^{81}$ Alectinib is not a substrate of P-glycoprotein, suggesting that it may reach effective therapeutic concentrations in the brain (Table 2). ${ }^{71}$ Brain tumor regression was observed in mice treated with alectinib and in patients with ALK-positive NSCLC who did not receive brain radiotherapy. ${ }^{82}$ There is also evidence that alectinib has activity in patients with leptomeningeal carcinomatosis. ${ }^{83}$

Alectinib has been tested in two phase II clinical trials in crizotinib-resistant ALK-positive NSCLC, including central nervous system (CNS) metastases (Table 1). In the NP28673 trial, the ORR was 50\% and median PFS was 8.9 months (Table 1). ${ }^{84}$ The efficacy of alectinib in patients with brain metastasis was confirmed by a CNS DCR of $83 \%$ (Table 2 ). ${ }^{84}$ Of the 35 patients with baseline measurable CNS lesions, IC-ORR was 57\%. Among the 84 patients with baseline CNS metastases, 23 (27\%) achieved a CNS DCR, and the overall IC-DCR was $83 \%$. The IC-duration of response (IC-DOR) for these 84 patients was 10.3 months (Table 2). ${ }^{84}$ In the NP28761 trial, an ORR of 48\% was achieved with 13.5 months median DOR. The estimated median PFS among all the patients treated was 8.1 months, while the estimated 1 -year OS was $71 \%$ (Table 1 ). ${ }^{85}$

Two twin randomized phase III trials are currently ongoing comparing alectinib with crizotinib as first-line treatment in patients with ALK-positive advanced NSCLC who had not been previously treated with an ALK inhibitor: the worldwide ALEX trial (NCT02075840) and the Japan J-ALEX (JapicCTI-132316). Both trials included were also designed to investigate the potential superiority of alectinib over crizotinib for the management of brain metastases.
The preliminary data of J-ALEX presented during the American Society of Clinical Oncology Annual Meeting 2016, based on 207 enrolled patients, showed reduced risk of disease worsening or death (PFS) by 66\% in favor of alectinib compared with crizotinib (hazard ratio $=0.34,99 \%$ CI: $0.17-0.70, P<0.0001)$. Median PFS was not reached in the alectinib arm (95\% CI: 20.3 months not estimated) vs 10.2 months in the crizotinib arm (95\% CI: 8.2-12). ${ }^{86}$

A second phase III trial is comparing alectinib with pemetrexed in patients with ALK-positive NSCLC previously treated with platinum-based chemotherapy and crizotinib (NCT02604342).

Alectinib is well tolerated with the majority of AEs reported being grades I-II. The most common are constipation, fatigue, myalgia, and peripheral edema. Grade III-IV AEs include increases in blood creatinine phosphokinase, ALT, and AST. Dose interruption has been reported in 36\% of patients and dose reduction in $16 \%$. The overall percentage of serious AEs was $15 \%$. Only $2 \%$ of patients discontinued the treatment due to AEs. ${ }^{84,85}$

In 2014, alectinib was approved in Japan, based on the results of a Japanese phase I/II clinical study (AF-001JP), for patients with NSCLC and ALK translocations. Afterward in 2015, FDA approved alectinib in the US, for crizotinib-resistant/ intolerant patients with ALK-positive NSCLC. In the same year, a new drug application was filed to the EMA.

\section{Mechanisms of resistance to alectinib}

Similar to the experience with crizotinib, mechanisms of acquired resistance to alectinib involve secondary ALK mutations that reduce the affinity binding and activation of alternative signaling pathways. Three secondary mutations have been identified in the ALK TK domain: V1180L, I1171T, and I1171N (Table 3). ${ }^{65,87}$ V1180L was isolated from the ALK-positive H3122 NSCLC cell line and became resistant to alectinib after 7 months of drug exposure. The mutation consists of a guanine $(\mathrm{G})$ to cytosine $(\mathrm{C})$ substitution at nucleotide 3538 , resulting in a valine $(\mathrm{V})$ to leucine $(\mathrm{L})$ change at codon 1180 (V1180L). It is located near the gatekeeper residue and confers sensitivity to ceritinib. A thymine (T) to cytosine (C) mutation at codon 3512 , leading to an isoleucine (I) to threonine (T) amino acid substitution at codon 1171 (I1171T), was detected in a patient who progressed while on treatment with alectinib (Table 3). An additional mutation at codon 3512, resulting in an isoleucine (I) to asparagine (N) change (I1171N), was described in another patient at alectinib recurrence. I1171 T/N mutations are located in the $\alpha-\mathrm{C}$ helix, prevent formation of the hydrogen bond between alectinib and ALK and confer sensitivity to ceritinib. 
In vitro findings indicate that the activation of alternative signaling pathways contribute to alectinib resistance. In particular, an increase in both phosphorylated EGFR and human epidermal growth factor receptor 2 was observed in $\mathrm{H} 1322$ ALK-positive NSCLC cell lines with acquired resistance to alectinib,${ }^{87}$ and combinatorial treatment with alectinib and afatinib increased apoptosis and suppressed phosphorylated AKT and ERK. Among the ligands responsible for EGFR stimulation, transforming growth factor alpha (TGF $\alpha)$ is the most crucial, as observed after TGF $\alpha$ and EGF knockdown. Co-treatment with alectinib and afatinib was an effective strategy in a xenograft model. Moreover, analogous to the experience with ceritinib, activation of IGF-1R and NRG-1/ HER3 was observed in H2228 NSCLC cell lines resistant to alectinib. Finally, EMT activation resulting from autocrine hepatic growth factor stimulation was identified as another strategy to bypass ALK inhibition by alectinib..$^{88,89}$ These findings provide the preclinical bases to investigate combinatorial treatment strategies in patients with NSCLC receiving alectinib and confirm the high clinical value of tumor re-biopsy at recurrence in molecularly defined patients on TKIs.

Transformation of the primary lung lesion to small cell lung cancer (SCLC) was reported in a 67-year-old female with ALK-positive NSCLC progressing to alectinib, previously treated with concomitant chemoradiotherapy, crizotinib, and different chemotherapy regimens. The re-biopsy of the primary lung lesion at progression to alectinib showed the presence of SCLC (CD56 ${ }^{+}$, synaptophysin+, TTF-1-), carrying the EML4-ALK fusion gene. ${ }^{89}$ Transformation from NSCLC to SCLC represents an acquired resistance mechanism occurring in $~ 5 \%-14 \%$ of patients with EGFR-mutant NSCLC treated with EGFR-TKIs..$^{90}$ The biologic explanation for the transformation of ALK-positive NSCLC to SCLC is not yet understood but two cases of patients with SCLC harboring EML4-ALK fusion gene have been previously reported. ${ }^{91,92}$ Recently, in a 72-year-old former smoker with a stage IV ALK-positive NSCLC who received crizotinib, radiographic evaluation at 2 months after beginning crizotinib showed a response in lung and liver lesions but disease progression in a perigastric lymph node, a jejunal lesion and subcutaneous nodules. The biopsy of the subcutaneous nodule revealed a neuroendocrine tumor $\left(\mathrm{TTF} 1+, \mathrm{CD} 56^{-}\right) .{ }^{93}$ The cases described suggest the presence of heterogeneous disease, not developing under the selected pressure of ALK inhibition, but actually present from the beginning.

\section{Brigatinib (AP26II3)}

Brigatinib is a novel ALK TKI that overcomes crizotinib resistance and shows great activity against the ALK TK gatekeeper mutations L1196M and G1202R (Figure 5). ${ }^{94}$ Brigatinib has also demonstrated activity against ROS1 and mutant EGFR harboring T790M resistance mutation. ${ }^{95}$ The antitumor activity and safety profile of brigatinib are being evaluated in a phase I/II trial (NCT01449461). Patients with treatment-naïve or crizotinib-resistant ALK-positive NSCLC, with or without CNS metastases, have been enrolled. ${ }^{95,96}$ An updated efficacy analysis showed that in patients with crizotinib-resistance disease, the ORR was $71 \%$, median PFS was 13.4 months and DOR was 9.9 months (Table 1). In the small group of crizotinib-naïve patients, the ORR was $100 \%$, while median PFS and DOR have not yet been reached. ${ }^{97}$ Among the patients with measurable brain disease, the IC-ORR was $53 \%$. Among patients with no measurable brain disease, the IC-ORR was $33 \%$. In the group of patients who had not received prior brain radiotherapy, the IC-ORR was $56 \%$ for those with measurable disease and $50 \%$ for those without. Median IC-PFS was 15.6 months, and the median IC-DOR was 18.9 months (Table 2) ${ }^{96} \mathrm{~A}$ subsequent phase II trial (NCT02094573) of brigatinib for ALK+ NSCLC progressing to crizotinib has completed enrollment. It is notable that the secondary objectives of the trial included the measurement of IC-ORR in patients with brain metastases through multiple magnetic resonance imaging assessments.

Brigatinib received a breakthrough therapy designation from the FDA in October 2014 for ALK-positive crizotinib-resistant NSCLC. The phase II ALTA (ALK in Lung cancer Trial of AP26113) trial enrolled 222 patients with ALK-positive NSCLC pretreated with crizotinib, who were randomized between two different doses of brigatinib, $90 \mathrm{mg}$ once daily and $180 \mathrm{mg}$ once daily. The preliminary results showed that $54 \%$ of patients receiving $180 \mathrm{mg}$ achieved confirmed objective response, with a median PFS of 12.9 months. Approximately $77 \%$ of patients with measurable brain disease had confirmed IC-ORR. ${ }^{98}$

Brigatinib is well tolerated, with the most common treatment-related $\mathrm{AE}$ being nausea, fatigue, diarrhea, headache, and cough. Serious AEs reported ( $\geq 2 \%$ frequency;

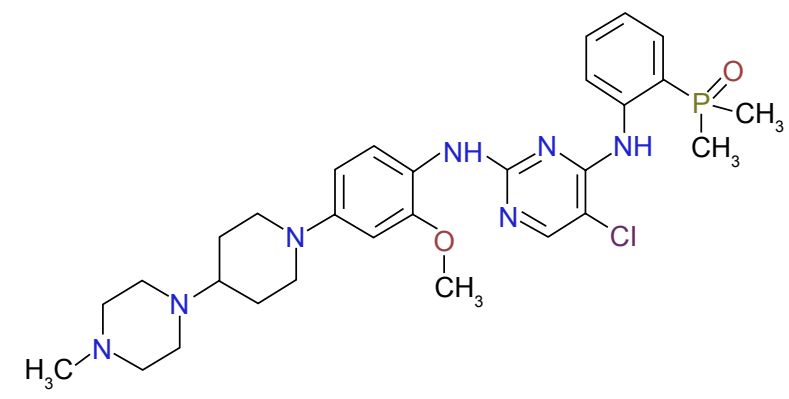

Figure 5 Brigatinib structure. 
any cause) are dyspnea, pneumonia, hypoxia, pulmonary embolism, and pyrexia.

In 2014, brigatinib received a breakthrough therapy designation from the FDA for the treatment of patients with ALK+ NSCLC whose disease is resistant to crizotinib.

\section{Lorlatinib (PF-06463922)}

Lorlatinib is a third-generation ATP-competitive selective ALK and ROS1 inhibitor, specifically designed and optimized to penetrate the blood-brain barrier (Figure 6). Preclinical data have shown that lorlatinib has activity against ALK-resistant mutations, including G1202R, ${ }^{67}$ and regresses IC tumors at doses much lower than the maximum tolerated dose. ${ }^{99}$ Lorlatinib is $\sim 10$-fold more potent against wild-type EML4-ALK and $\sim 40$-fold more potent against EML4-ALK L1196M compared with crizotinib. ${ }^{67,99}$ Preliminary results from the phase I/II trial in 41 patients with ALK-positive and 12 patients with ROS1-positive NSCLC with or without CNS metastases showed an ORR of $50 \%$. In the patients evaluable for IC response, the ORR was $60 \%$. The most common treatment-related AEs were grade I-II hypercholesterolemia, peripheral edema, and peripheral neuropathy. The only grade $\geq$ III treatment-related AE was hypercholesterolemia. ${ }^{100}$

Lorlatinib has not yet been approved by any regulatory agency.

\section{Mechanism of resistance to lorlatinib}

A novel ALK secondary mutation was identified in a 52-yearold female with EML4-ALK NSCLC who progressed to lorlatinib. ${ }^{101}$ She experienced disease recurrence on crizotinib due to the development of ALK C1156Y, no benefit from ceritinib and a partial response to lorlatinib that lasted 8 months. The tumor biopsy performed at the time of relapse to lorlatinib confirmed the $\mathrm{C} 1156 \mathrm{Y}$ and revealed the presence of a second ALK mutation in the same subclone, the L1198F, previously described as a gain-of-function mutation in

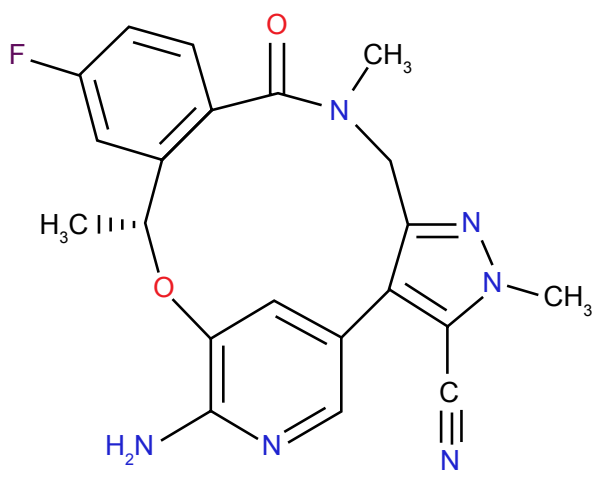

Figure 6 Lorlatinib structure. anaplastic thyroid cancer. ${ }^{102}$ The crystallographic structure of L1198F showed that it is located near the ATP-binding site. Phenylalanine interferes with binding to lorlatinib and other second-generation ALK TKIs, while enhancing binding to crizotinib (Table 3). The C1156Y mutation does not interfere with crizotinib binding, but does increase kinase activity of the ALK receptor. The patient received crizotinib and dramatically improved, suggesting that the development of the L1198F mutation on lorlatinib treatment overcomes resistance mediated by $\mathrm{C} 1156 \mathrm{Y}$. The double mutation resensitizes cancer cells to crizotinib, probably as a result of the major inhibitory effect induced by crizotinib that encompasses the C1156Y-augmented kinase activity.

\section{Open questions: combination treatments}

A critical issue concerns the development of combinatorial therapeutic strategies to delay the emergence of acquired resistance. Targeted agents in solid tumors generally induce incomplete remissions. The residual disease is composed of tumor cells that are not responsive to treatment, because of intrinsic resistance, pharmacokinetic failure, or tumor cell adaptation. The final result is tumor progression, and polytherapy strategies are needed to prevent treatment failure. ${ }^{103}$ The biological bases to design synthetic lethal combinations are not fully understood due to the lack of cancer models and the lack of instruments that are able to deeply analyze the signaling transduction pathways activated in each patient. Recently, cell lines from patients with ALK-positive NSCLC, progressing on ALK inhibition, were developed, and agents, targeting different oncogenes, were tested in the presence or absence of the primary ALK inhibitor. ${ }^{68}$ Concomitant treatment with an ALK inhibitor and the SRC inhibitor saracatinib resulted in high sensitivity in six out of nine of the patientderived models tested. NGS did not find any mutations in the genes belonging to the SRC family kinase, and the pathway transduction analysis revealed a direct link between the ALK, its downstream effectors, and SRC regulation, since ALK inhibition favored SRC activation. The combination of ceritinib and saracatinib significantly suppressed the viability of cells, compared with ceritinib alone, in cell lines established from an ALK-positive patient progressing to crizotinib, due to the development of the L1196M gatekeeper mutation, suggesting this as a promising up-front therapeutic strategy to enhance ALK inhibition efficacy. It should be kept in mind that secondary mutations represent only a minority of the acquired resistance mechanisms occurring under ALK inhibitors, and, as extensively described earlier, compensatory signaling pathways can emerge in the course of 
Table 4 Ongoing studies with combination treatments

\begin{tabular}{|c|c|c|c|}
\hline Study & Patients & Phase & Combination \\
\hline \multicolumn{4}{|c|}{ PD-I/PD-LI inhibitors } \\
\hline NCT025III 84 & ALK naïve & $\mathrm{lb}$ & Crizotinib + pembrolizumab \\
\hline \multirow[t]{2}{*}{ NCT0I998I26 } & $\mathrm{ALK}+$ & $\mathrm{I}$ & Crizotinib + ipilimumab \\
\hline & & & Crizotinib + nivolumab \\
\hline NCT02584634 & ALK+, no prior PD-I/PD-LI & $\mathrm{lb} / \mathrm{Il}$ & Crizotinib/lorlatinib + avelumab \\
\hline NCT02013219 & ALK+ & $\mathrm{lb}$ & Alectinib + atezolizumab \\
\hline \multicolumn{4}{|l|}{ Hsp90 inhibitors } \\
\hline NCT0I772797 & ALK+ previously treated & $\mathrm{lb}$ & Ceritinib + AUY922 \\
\hline STA-9090 & Crizotinib-naïve & 1 & Crizotinib + ganetespib \\
\hline \multicolumn{4}{|c|}{ Other combinations } \\
\hline$S 1300$ & ALK + progressing on crizotinib & $\|$ & Pemetrexed \pm crizotinib \\
\hline NCT02292550 & ALK+ & $\mathrm{lb} / \mathrm{II}$ & Ceritinib + LEEOII \\
\hline NCT0252I05I & ALK+ & $\mathrm{I} / \mathrm{II}$ & Alectinib + bevacizumab \\
\hline
\end{tabular}

Abbreviations: ALK, anaplastic lymphoma kinase; Hsp90, heat shock proteins 90; PD-LI, programmed cell death ligand I.

ALK treatment, highlighting the potential role of synthetic combinations to delay progression. Phase I/II studies are currently evaluating the safety and activity of ALK inhibitors, combined with drugs suppressing the heat shock proteins 90 (Hsp90) or agents targeting the PD-1/PD-L1 signaling pathway (Table 4). The EML4-ALK protein is a client protein of the Hsp90 chaperone that is responsible for EML4-ALK folding and stability. ${ }^{104,105}$ Hsp90 inhibition induces the misfolding of the EML4-ALK protein, thus favoring its degradation by the proteasome system. Ganetespib, IPI504, and AUY922 showed a promising activity in patients with ALK-positive NSCLC as single agent, ${ }^{106-108}$ and combination studies with ALK inhibitors are currently ongoing. The findings that downstream effectors of EML4-ALK favor PD-L1 upregulation, promoting immune escape, and the initial data showing high levels of PD-L1 expression in patients with ALK-positive NSCLC ${ }^{19}$ prompted to evaluate the activity of PD-1/PD-L1 inhibitors also in this subgroup of patients. Preliminary results indicate the low efficacy of this class of compounds in ALK-positive patients, and the tissue retrospective analysis from crizotinib-naïve cases showed low PD-L1 expression and CD8 ${ }^{+}$tumor-infiltrating lymphocytes. ${ }^{109}$ Moreover, the expression levels further decreased after the treatment with ALK inhibitors, suggesting the innate immune resistance as the reason for the limited effectiveness observed in ALK-positive patients under PD-1/ PD-L1 inhibitors. The ongoing studies will elucidate whether the efficacy would be improved by the combinatorial suppression of PD-1/PD-L1 and ALK pathways.

\section{Conclusion}

The only way to improve cancer treatment is the design of clinical trials that aim to investigate, through the use of liquid biopsy and proteomic, genetic and epigenetic analyses, the biology of the residual disease at the point of maximal response, to define personalized approaches.

\section{Disclosure}

The authors report no conflicts of interest in this work.

\section{References}

1. Torre LA, Siegel RL, Ward EM, Jemal A. Global cancer incidence and mortality rates and trends - an update. Cancer Epidemiol Biomarkers Prev. 2016;25(1):16-27.

2. Rosell R, Karachaliou N. Large-scale screening for somatic mutations in lung cancer. Lancet. 2016;387(10026):1354-1356.

3. Rosell R, Moran T, Queralt C, et al; Spanish Lung Cancer Group. Screening for epidermal growth factor receptor mutations in lung cancer. N Engl J Med. 2009;361(10):958-967.

4. Kris MG, Johnson BE, Berry LD, et al. Using multiplexed assays of oncogenic drivers in lung cancers to select targeted drugs. JAMA. 2014; 311(19):1998-2006.

5. Soda M, Choi YL, Enomoto M, et al. Identification of the transforming EML4-ALK fusion gene in non-small-cell lung cancer. Nature. 2007; 448(7153):561-566.

6. Kwak EL, Bang YJ, Camidge DR, et al. Anaplastic lymphoma kinase inhibition in non-small-cell lung cancer. N Engl J Med. 2010;363(18): 1693-1703.

7. Shaw AT, Kim DW, Nakagawa K, et al. Crizotinib versus chemotherapy in advanced ALK-positive lung cancer. $N$ Engl J Med. 2013; 368(25):2385-2394.

8. Solomon BJ, Mok T, Kim DW, et al; PROFILE 1014 Investigators. First-line crizotinib versus chemotherapy in ALK-positive lung cancer. N Engl J Med. 2014;371(23):2167-2177.

9. Eichenmuller B, Everley P, Palange J, Lepley D, Suprenant KA. The human EMAP-like protein-70 (ELP70) is a microtubule destabilizer that localizes to the mitotic apparatus. J Biol Chem. 2002;277(2): 1301-1309.

10. Horn L, Pao W. EML4-ALK: honing in on a new target in non-smallcell lung cancer. J Clin Oncol. 2009;27(26):4232-4235.

11. Choi YL, Takeuchi K, Soda M, et al. Identification of novel isoforms of the EML4-ALK transforming gene in non-small cell lung cancer. Cancer Res. 2008;68(13):4971-4976.

12. Takeuchi K, Choi YL, Soda M, et al. Multiplex reverse transcriptionPCR screening for EML4-ALK fusion transcripts. Clin Cancer Res. 2008;14(20):6618-6624.

13. Richards MW, O'Regan L, Roth D, et al. Microtubule association of EML proteins and the EML4-ALK variant 3 oncoprotein require an N-terminal trimerization domain. Biochem J. 2015;467(3):529-536. 
14. Richards MW, Law EW, Rennalls LP, et al. Crystal structure of EML1 reveals the basis for Hsp90 dependence of oncogenic EML4-ALK by disruption of an atypical beta-propeller domain. Proc Natl Acad Sci U S A. 2014;111(14):5195-5200.

15. Heuckmann JM, Balke-Want H, Malchers F, et al. Differential protein stability and ALK inhibitor sensitivity of EML4-ALK fusion variants. Clin Cancer Res. 2012;18(17):4682-4690.

16. Sasaki T, Rodig SJ, Chirieac LR, Janne PA. The biology and treatment of EML4-ALK non-small cell lung cancer. Eur J Cancer. 2010;46(10): $1773-1780$

17. Camidge DR, Doebele RC. Treating ALK-positive lung cancer-early successes and future challenges. Nat Rev Clin Oncol. 2012;9(5):268-277.

18. Hrustanovic G, Olivas V, Pazarentzos E, et al. RAS-MAPK dependence underlies a rational polytherapy strategy in EML4-ALK-positive lung cancer. Nat Med. 2015;21(9):1038-1047.

19. Ota K, Azuma K, Kawahara A, et al. Induction of PD-L1 expression by the EML4-ALK oncoprotein and downstream signaling pathways in nonsmall cell lung cancer. Clin Cancer Res. 2015;21(17):4014-4021.

20. Zhao F, Xu M, Lei H, et al. Clinicopathological characteristics of patients with non-small-cell lung cancer who harbor EML4-ALK fusion gene: a meta-analysis. PLoS One. 2015;10(2):e0117333.

21. Shaw AT, Yeap BY, Mino-Kenudson M, et al. Clinical features and outcome of patients with non-small-cell lung cancer who harbor EML4ALK. J Clin Oncol. 2009;27(26):4247-4253.

22. Paik JH, Choe G, Kim H, et al. Screening of anaplastic lymphoma kinase rearrangement by immunohistochemistry in non-small cell lung cancer: correlation with fluorescence in situ hybridization. $J$ Thorac Oncol. 2011;6(3):466-472.

23. Lee T, Lee B, Choi YL, Han J, Ahn MJ, Um SW. Non-small cell lung cancer with concomitant EGFR, KRAS, and ALK mutation: clinicopathologic features of 12 cases. J Pathol Transl Med. 2016;50(3): 197-203.

24. Johung KL, Yeh N, Desai NB, et al. Extended survival and prognostic factors for patients with ALK-rearranged non-small-cell lung cancer and brain metastasis. J Clin Oncol. 2016;34(2):123-129.

25. Cai W, Lin D, Wu C, et al. Intratumoral heterogeneity of ALK-rearranged and ALK/EGFR coaltered lung adenocarcinoma. J Clin Oncol. 2015; 33(32):3701-3709.

26. Oh SJ, Noh KH, Lee YH, et al. Targeting stemness is an effective strategy to control EML4-ALK+ non-small cell lung cancer cells. Oncotarget. 2015;6(37):40255-40267.

27. Lee KW, Yook JY, Son MY, et al. Rapamycin promotes the osteoblastic differentiation of human embryonic stem cells by blocking the mTOR pathway and stimulating the BMP/Smad pathway. Stem Cells Dev. 2010;19(4):557-568.

28. Karachaliou N, Rosell R. Optimal detection of ALK rearranged lung adenocarcinomas. J Thorac Oncol. 2013;8(3):255-256.

29. Marchetti A, Di Lorito A, Pace MV, et al. ALK protein analysis by IHC staining after recent regulatory changes: a comparison of two widely used approaches, revision of the literature, and a new testing algorithm. J Thorac Oncol. 2016;11(4):487-495.

30. Teixido C, Karachaliou N, Peg V, Gimenez-Capitan A, Rosell R. Concordance of IHC, FISH and RT-PCR for EML4-ALK rearrangements. Transl Lung Cancer Res. 2014;3(2):70-74.

31. Veldman-Jones MH, Brant R, Rooney C, et al. Evaluating robustness and sensitivity of the NanoString Technologies nCounter Platform to enable multiplexed gene expression analysis of clinical samples. Cancer Res. 2015;75(13):2587-2593.

32. Lira ME, Kim TM, Huang D, et al. Multiplexed gene expression and fusion transcript analysis to detect ALK fusions in lung cancer. $J \mathrm{Mol}$ Diagn. 2013;15(1):51-61.

33. Ilie $\mathrm{M}$, Long $\mathrm{E}$, Butori $\mathrm{C}$, et al. ALK-gene rearrangement: a comparative analysis on circulating tumour cells and tumour tissue from patients with lung adenocarcinoma. Ann Oncol. 2012;23(11):2907-2913.

34. Pailler E, Adam J, Barthelemy A, et al. Detection of circulating tumor cells harboring a unique ALK rearrangement in ALK-positive nonsmall-cell lung cancer. J Clin Oncol. 2013;31(18):2273-2281.
35. Tan CL, Lim TH, Lim T, et al. Concordance of anaplastic lymphoma kinase (ALK) gene rearrangements between circulating tumor cells and tumor in non-small cell lung cancer. Oncotarget. 2016;7(17): 23251-23262.

36. Skog J, Wurdinger T, van Rijn S, et al. Glioblastoma microvesicles transport RNA and proteins that promote tumour growth and provide diagnostic biomarkers. Nat Cell Biol. 2008;10(12):1470-1476.

37. Nilsson J, Skog J, Nordstrand A, et al. Prostate cancer-derived urine exosomes: a novel approach to biomarkers for prostate cancer. $\mathrm{Br} J$ Cancer. 2009;100(10):1603-1607.

38. Goubran HA, Stakiw J, Radosevic M, Burnouf T. Platelets effects on tumor growth. Semin Oncol. 2014;41(3):359-369.

39. Best MG, Sol N, Kooi I, et al. RNA-Seq of tumor-educated platelets enables blood-based pan-cancer, multiclass, and molecular pathway cancer diagnostics. Cancer Cell. 2015;28(5):666-676.

40. Nilsson RJ, Karachaliou N, Berenguer J, et al. Rearranged EML4-ALK fusion transcripts sequester in circulating blood platelets and enable blood-based crizotinib response monitoring in non-small-cell lung cancer. Oncotarget. 2016;7(1):1066-1075.

41. Christensen JG, Zou HY, Arango ME, et al. Cytoreductive antitumor activity of PF-2341066, a novel inhibitor of anaplastic lymphoma kinase and c-Met, in experimental models of anaplastic large-cell lymphoma. Mol Cancer Ther. 2007;6(12 Pt 1):3314-3322.

42. Cui JJ, Tran-Dube M, Shen H, et al. Structure based drug design of crizotinib (PF-02341066), a potent and selective dual inhibitor of mesenchymal-epithelial transition factor (c-MET) kinase and anaplastic lymphoma kinase (ALK). J Med Chem. 2011;54(18):6342-6363.

43. Camidge DR, Bang YJ, Kwak EL, et al. Activity and safety of crizotinib in patients with ALK-positive non-small-cell lung cancer: updated results from a phase 1 study. Lancet Oncol. 2012;13(10):1011-1019.

44. Kim DW, Ahn MJ, Shi Y, et al. Results of a global phase II study with crizotinib in ALK-positive non-small cell lung cancer NSCLC. J Clin Oncol. 2012;30(suppl):abstr7533.

45. Takezawa K, Okamoto I, Okamoto W, et al. Thymidylate synthase as a determinant of pemetrexed sensitivity in non-small cell lung cancer. Br J Cancer. 2011;104(10):1594-1601.

46. Takeda M, Okamoto I, Sakai K, et al. Successful long-term treatment with pemetrexed of NSCLC associated with EML4-ALK and low thymidylate synthase expression. Clin Lung Cancer. 2012;13(2):157-159.

47. Gridelli C, Peters S, Sgambato A, Casaluce F, Adjei AA, Ciardiello F. ALK inhibitors in the treatment of advanced NSCLC. Cancer Treat Rev. 2014;40(2):300-306.

48. Rangachari D, Yamaguchi N, VanderLaan PA, et al. Brain metastases in patients with EGFR-mutated or ALK-rearranged non-small-cell lung cancers. Lung Cancer. 2015;88(1):108-111.

49. Costa DB, Shaw AT, Ou SH, et al. Clinical experience with crizotinib in patients with advanced ALK-rearranged non-small-cell lung cancer and brain metastases. J Clin Oncol. 2015;33(17):1881-1888.

50. Costa DB, Kobayashi S, Pandya SS, et al. CSF concentration of the anaplastic lymphoma kinase inhibitor crizotinib. J Clin Oncol. 2011; 29(15):e443-e445.

51. Solomon BJ, Cappuzzo F, Felip E, et al. Intracranial efficacy of crizotinib versus chemotherapy in patients with advanced ALK-positive non-small-cell lung cancer: results from PROFILE 1014. J Clin Oncol. 2016;34(24):2858-2865.

52. Cappuzzo F, Moro-Sibilot D, Gautschi O, et al. Management of crizotinib therapy for ALK-rearranged non-small cell lung carcinoma: an expert consensus. Lung Cancer. 2015;87(2):89-95.

53. Doebele RC, Pilling AB, Aisner DL, et al. Mechanisms of resistance to crizotinib in patients with ALK gene rearranged non-small cell lung cancer. Clin Cancer Res. 2012;18(5):1472-1482.

54. Katayama R, Shaw AT, Khan TM, et al. Mechanisms of acquired crizotinib resistance in ALK-rearranged lung cancers. Sci Transl Med. 2012;4(120):120ra17.

55. Choi YL, Soda M, Yamashita Y, et al. EML4-ALK mutations in lung cancer that confer resistance to ALK inhibitors. $N$ Engl J Med. 2010; 363(18):1734-1739. 
56. Lovly CM, Pao W. Escaping ALK inhibition: mechanisms of and strategies to overcome resistance. Sci Transl Med. 2012;4(120): $120 \mathrm{ps} 2$.

57. Sun $\mathrm{HY}$, Ji FQ. A molecular dynamics investigation on the crizotinib resistance mechanism of C1156Y mutation in ALK. Biochem Biophys Res Commun. 2012;423(2):319-324.

58. Sasaki T, Koivunen J, Ogino A, et al. A novel ALK secondary mutation and EGFR signaling cause resistance to ALK kinase inhibitors. Cancer Res. 2011;71(18):6051-6060.

59. Kumar A, Ramanathan K. Exploring the structural and functional impact of the ALK F1174L mutation using bioinformatics approach J Mol Model. 2014;20(7):2324.

60. Sasaki T, Okuda K, Zheng W, et al. The neuroblastoma-associated F1174L ALK mutation causes resistance to an ALK kinase inhibitor in ALK-translocated cancers. Cancer Res. 2010;70(24):10038-10043.

61. Kodityal S, Elvin JA, Squillace R, et al. A novel acquired ALK F1245C mutation confers resistance to crizotinib in ALK-positive NSCLC but is sensitive to ceritinib. Lung Cancer. 2016;92:19-21.

62. Bresler SC, Weiser DA, Huwe PJ, et al. ALK mutations confer differential oncogenic activation and sensitivity to ALK inhibition therapy in neuroblastoma. Cancer Cell. 2014;26(5):682-694.

63. Friboulet L, Li N, Katayama R, et al. The ALK inhibitor ceritinib overcomes crizotinib resistance in non-small cell lung cancer. Cancer Discov. 2014;4(6):662-673.

64. Kodama T, Tsukaguchi T, Yoshida M, Kondoh O, Sakamoto H. Selective ALK inhibitor alectinib with potent antitumor activity in models of crizotinib resistance. Cancer Lett. 2014;351(2):215-221.

65. Rosell R, Karachaliou N, Wolf J, Ou SH. ALK and ROS1 non-smallcell lung cancer: two molecular subgroups sensitive to targeted therapy. Lancet Respir Med. 2014;2(12):966-968.

66. Yoshimura Y, Kurasawa M, Yorozu K, Puig O, Bordogna W, Harada N. Antitumor activity of alectinib, a selective ALK inhibitor, in an ALKpositive NSCLC cell line harboring G1269A mutation: efficacy of alectinib against ALK G1269A mutated cells. Cancer Chemother Pharmacol. 2016;77(3):623-628.

67. Zou HY, Friboulet L, Kodack DP, et al. PF-06463922, an ALK/ROS1 inhibitor, overcomes resistance to first and second generation ALK inhibitors in preclinical models. Cancer Cell. 2015;28(1):70-81.

68. Crystal AS, Shaw AT, Sequist LV, et al. Patient-derived models of acquired resistance can identify effective drug combinations for cancer. Science. 2014;346(6216):1480-1486.

69. Marsilje TH, Pei W, Chen B, et al. Synthesis, structure-activity relationships, and in vivo efficacy of the novel potent and selective anaplastic lymphoma kinase (ALK) inhibitor 5-chloro-N2-(2isopropoxy-5-methyl-4-(piperidin-4-yl)phenyl)-N4-(2-(isopropylsulf onyl)phenyl)pyrimidine-2,4-diamine (LDK378) currently in phase 1 and phase 2 clinical trials. $J$ Med Chem. 2013;56:5675-5690.

70. Kim DW, Mehra R, Tan DS, et al. Activity and safety of ceritinib in patients with ALK-rearranged non-small-cell lung cancer (ASCEND-1): updated results from the multicentre, open-label, phase 1 trial. Lancet Oncol. 2016;17(4):452-463.

71. Kort A, Sparidans RW, Wagenaar E, Beijnen JH, Schinkel AH. Brain accumulation of the EML4-ALK inhibitor ceritinib is restricted by P-glycoprotein (P-GP/ABCB1) and breast cancer resistance protein (BCRP/ABCG2). Pharmacol Res. 2015;102:200-207.

72. Crinò L, Ahn MJ, De Marinis F, et al. Multicenter phase II study of whole-body and intracranial activity with ceritinib in patients with ALKrearranged non-small-cell lung cancer previously treated with chemotherapy and crizotinib: results from ASCEND-2. J Clin Oncol. 2016 34(24):2866-2873.

73. Felip E, Orlov S, Park K, et al. ASCEND-3: a single-arm, open-label, multicenter phase II study of ceritinib in ALKi-naïve adult patients (pts) with ALK-rearranged (ALK+) non-small cell lung cancer (NSCLC). J Clin Oncol. 2015;33:8060

74. Sullivan I, Planchard D. ALK inhibitors in non-small cell lung cancer: the latest evidence and developments. Ther Adv Med Oncol. 2016;8(1): $32-47$.
75. Toyokawa G, Inamasu E, Shimamatsu S, et al. Identification of a novel ALK G1123S mutation in a patient with ALK-rearranged non-small-cell lung cancer exhibiting resistance to ceritinib. J Thorac Oncol. 2015; 10(7):e55-e57.

76. Dong X, Fernandez-Salas E, Li E, Wang S. Elucidation of resistance mechanisms to second-generation ALK inhibitors alectinib and ceritinib in non-small cell lung cancer cells. Neoplasia. 2016;18(3):162-171.

77. Sakamoto H, Tsukaguchi T, Hiroshima S, et al. CH5424802, a selective ALK inhibitor capable of blocking the resistant gatekeeper mutant. Cancer Cell. 2011;19(5):679-690.

78. Kinoshita K, Asoh K, Furuichi N, et al. Design and synthesis of a highly selective, orally active and potent anaplastic lymphoma kinase inhibitor (CH5424802). Bioorg Med Chem. 2012;20(3):1271-1280.

79. Seto T, Kiura K, Nishio M, et al. CH5424802 (RO5424802) for patients with ALK-rearranged advanced non-small-cell lung cancer (AF-001JP study): a single-arm, open-label, phase 1-2 study. Lancet Oncol.2013;14: 590-598.

80. Ohe Y, Nishio M, Kiura K, et al. A phase I/II study with a CNS-penetrant, selective ALK inhibitor alectinib in ALK-rearranged non-small cell lung cancer (ALK+ NSCLC) patients (pts): updates on progression free survival (PFS) and safety results from AF-001JP. J Clin Oncol. 2015; 33(suppl):abstr8061.

81. Gadgeel SM, Gandhi L, Riely GJ, et al. Safety and activity of alectinib against systemic disease and brain metastases in patients with crizotinibresistant ALK-rearranged non-small-cell lung cancer (AF-002JG): results from the dose-finding portion of a phase 1/2 study. Lancet Oncol. 2014; 15(10):1119-1128.

82. Kodama T, Hasegawa M, Takanashi K, Sakurai Y, Kondoh O, Sakamoto H. Antitumor activity of the selective ALK inhibitor alectinib in models of intracranial metastases. Cancer Chemother Pharmacol. 2014; 74(5):1023-1028.

83. Gainor JF, Sherman CA, Willoughby K, et al. Alectinib salvages CNS relapses in ALK-positive lung cancer patients previously treated with crizotinib and ceritinib. J Thorac Oncol. 2015;10(2):232-236.

84. Ou SH, Ahn JS, De Petris L, et al. Alectinib in crizotinib-refractory ALK-rearranged non-small-cell lung cancer: a phase II global study. J Clin Oncol. 2016;34(7):661-668.

85. Shaw AT, Gandhi L, Gadgeel S, et al; Study Investigators. Alectinib in ALK-positive, crizotinib-resistant, non-small-cell lung cancer: a singlegroup, multicentre, phase 2 trial. Lancet Oncol. 2016;17(2):234-242.

86. Nokihara H, Hida T, Kondo M, et al. Alectinib (ALC) versus crizotinib (CRZ) in ALK-inhibitor naive $A L K$-positive non-small cell lung cancer ( $A L K+$ NSCLC): primary results from the J-ALEX study. J Clin Oncol. 2016;34(suppl):abstr9008

87. Katayama R, Friboulet L, Koike S, et al. Two novel ALK mutations mediate acquired resistance to the next-generation ALK inhibitor alectinib. Clin Cancer Res. 2014;20(22):5686-5696.

88. Isozaki $\mathrm{H}$, Ichihara $\mathrm{E}$, Takigawa N, et al. Non-small cell lung cancer cells acquire resistance to the ALK inhibitor alectinib by activating alternative receptor tyrosine kinases. Cancer Res. 2016;76(6):1506-1516.

89. Tani T, Yasuda H, Hamamoto J, et al. Activation of EGFR bypass signaling by TGFalpha overexpression induces acquired resistance to alectinib in ALK-translocated lung cancer cells. Mol Cancer Ther. 2016;15(1):162-171.

90. Fujita S, Masago K, Katakami N, Yatabe Y. Transformation to SCLC after treatment with the ALK inhibitor alectinib.J Thorac Oncol. 2016; 11(6):e67-e72.

91. Toyokawa G, Taguchi K, Ohba T, et al. First case of combined small-cell lung cancer with adenocarcinoma harboring EML4-ALK fusion and an exon 19 EGFR mutation in each histological component. $J$ Thorac Oncol. 2012;7(12):e39-e41.

92. Oser MG, Niederst MJ, Sequist LV, Engelman JA. Transformation from non-small-cell lung cancer to small-cell lung cancer: molecular drivers and cells of origin. Lancet Oncol. 2015;16(4):e165-e172.

93. Toyokawa G, Takenoyama M, Taguchi K, et al. An extremely rare case of small-cell lung cancer harboring variant 2 of the EML4-ALK fusion gene. Lung Cancer. 2013;81(3):487-490. 
94. Squillace RM, Anjum R, Miller D, et al. AP26113 possesses pan-inhibitory activity versus crizotinib-resistant ALK mutants and oncogenic ROS1 fusions. Cancer Res. 2013;73(8 Suppl): abstr 5655 .

95. Rivera VM, Wang F, Anjum R, et al. AP26113 is a dual ALK/EGFR inhibitor: characterization against EGFR T790M in cell and mouse models of NSCLC. Cancer Res. 2012;72:abstr1794.

96. Camidge R, Bazhenova L, Salgia R, et al. Safety and efficacy of brigatinib (AP26113) in advanced malignancies including ALK+ non-small cell lung cancer (NSCLC). J Clin Oncol. 2015;33(suppl): abstr8062.

97. Rosell R, Gettinger SN, Bazhenova LA, et al. 1330: Brigatinib efficacy and safety in patients (Pts) with anaplastic lymphoma kinase (ALK)positive (ALK+) non-small cell lung cancer (NSCLC) in a phase 1/2 trial. J Thorac Oncol. 2016;11(4 Suppl):S114.

98. Kim D-W, Marcello T, Ahn M-J, et al. Brigatinib (BRG) in patients (pts) with crizotinib (CRZ)-refractory ALK+ non-small cell lung cancer (NSCLC): first report of efficacy and safety from a pivotal randomized phase (ph) 2 trial (ALTA). J Clin Oncol. 2016;34(suppl): abstr9007.

99. Johnson TW, Richardson PF, Bailey S, et al. Discovery of (10R)-7amino-12-fluoro-2,10,16-trimethyl-15-oxo-10,15,16,17-tetrahydro-2H-8,4-(m etheno)pyrazolo[4,3-h][2,5,11]-benzoxadiazacyclotetradeci ne-3-carbonitrile (PF-06463922), a macrocyclic inhibitor of anaplastic lymphoma kinase (ALK) and c-ros oncogene 1 (ROS1) with preclinical brain exposure and broad-spectrum potency against ALK-resistant mutations. J Med Chem. 2014;57:4720-4744.

100. Shaw AT, Bauer TM, Felip E, et al. Clinical activity and safety of PF-06463922 from a dose escalation study in patients with advanced ALK+ or ROS1+ NSCLC. J Clin Oncol. 2015;33(suppl):abstr8018.
101. Shaw AT, Friboulet L, Leshchiner I, et al. Resensitization to crizotinib by the lorlatinib ALK resistance mutation L1198F. N Engl J Med. 2016; 374(1):54-61.

102. Murugan AK, Xing M. Anaplastic thyroid cancers harbor novel oncogenic mutations of the ALK gene. Cancer Res. 2011;71(13): 4403-4411.

103. Bivona TG, Doebele RC. A framework for understanding and targeting residual disease in oncogene-driven solid cancers. Nat Med. 2016;22(5):472-478.

104. Chen Z, Sasaki T, Tan X, et al. Inhibition of ALK, PI3K/MEK, and HSP90 in murine lung adenocarcinoma induced by EML4-ALK fusion oncogene. Cancer Res. 2010;70(23):9827-9836.

105. Normant E, Paez G, West KA, et al. The Hsp90 inhibitor IPI-504 rapidly lowers EML4-ALK levels and induces tumor regression in ALK-driven NSCLC models. Oncogene. 2011;30(22):2581-2586.

106. Sequist LV, Gettinger S, Senzer NN, et al. Activity of IPI-504, a novel heat-shock protein 90 inhibitor, in patients with molecularly defined non-small-cell lung cancer. J Clin Oncol. 2010;28(33):4953-4960.

107. Felip E, Carcereny E, Barlesi F, et al. Phase II activity of the Hsp90 inhibitor AUY922 in patients with ALK-rearranged (ALK+) or EGFR mutated advanced non-small cell lung cancer (NSCLC). Ann Oncol. 2012;23:ix152-ix174.

108. Socinski MA, Goldman J, El-Hariry I, et al. A multicenter phase II study of ganetespib monotherapy in patients with genotypically defined advanced non-small cell lung cancer. Clin Cancer Res. 2013;19(11): 3068-3077.

109. Gainor JF, Shaw AT, Sequist LV, et al. EGFR mutations and ALK rearrangements are associated with low response rates to $\mathrm{PD}-1$ pathway blockade in non-small cell lung cancer (NSCLC): a retrospective analysis. Clin Cancer Res. Epub 2016 May 25.
OncoTargets and Therapy

\section{Publish your work in this journal}

OncoTargets and Therapy is an international, peer-reviewed, open access journal focusing on the pathological basis of all cancers, potential targets for therapy and treatment protocols employed to improve the management of cancer patients. The journal also focuses on the impact of management programs and new therapeutic agents and protocols on

\section{Dovepress}

patient perspectives such as quality of life, adherence and satisfaction The manuscript management system is completely online and includes a very quick and fair peer-review system, which is all easy to use. Visit http://www.dovepress.com/testimonials.php to read real quotes from published authors. 